\title{
"E TUDO FICA MELODIA" - OBSERVAÇÕES SOBRE A VERSIFICAÇÃO DO FAUSTO DE JENNY KLABIN SEGALL
}

Helmut Paul Erich Galle ${ }^{1}$

${ }^{1}$ Universidade de São Paulo, São Paulo, São Paulo, Brasil

\begin{abstract}
Resumo: O artigo analisa a tradução do Fausto de Goethe, realizada por Jenny Klabin Segall em relação aos versos usados no texto de partida e no texto de chegada. Considerando a estrutura plurimétrica do Fausto e as diferenças entre as prosódias alemã e portuguesa, analisa-se a estrutura métrica em exemplos de vários trechos do drama, comparando cada vez as decisões de Goethe e as opções da tradutora. Nota-se que os versos portugueses se orientam rigorosamente na extensão dos versos alemães, buscando "equivalentes" métricos onde isso era possível (no caso da estância/ terça rima e do alexandrino). $\mathrm{O}$ trabalho chega à conclusão de, embora que não haja metros portugueses que "imitam" iambos e troqueus, a escolha sistemática de versos com número par de sílabas para iambos alemães e ímpar para troqueus alemães produz um efeito rítmico diferenciado. Para os metros mais alheios da versificação brasileira (Knittelvers, Freie Rhythmen) a tradutora encontrou soluções originais que se aproximam ao efeito estético do original sem ultrapassar os limites da prosódia do português do Brasil.
\end{abstract}

Palavras-Chave: Literatura alemã; Goethe; Jenny Klabin Segall; Tradução Versificada

\section{"EVERYTHING BECOMES MELODY" - REMARKS ON JENNY KLABIN SEGALL'S VERSIFIED TRANSLATION OF FAUST}

Abstract: The article analyzes the translation of Goethe's Faust by Jenny Klabin Segall regarding the verses used in the source text and in the target text. Considering the plurimetric structure of Faust and the differences 
between German and Portuguese prosody, the metric structure of several sections of the drama is analyzed, comparing Goethe's and the translator's decisions. It can be stated that the Portuguese verses are strictly oriented in the extension of the German verses, looking for metric "equivalents" whenever this was possible (in the case of ottava rima stanza and alexandrine). It is concluded that, although there are no Portuguese meters that "imitate" iambic or trochaic verses, the choice of pair verses for German iambs and impair for German trochees produces a differentiated rhythmic effect. For meters more divergent from Brazilian versification (Knittelvers, Freie Rhythmen), the translator found original solutions which draw near to the aesthetical effect of the original without transgressing the limits of Brazilian prosody.

Keywords: German Literature; Goethe; Jenny Klabin Segall; Verse Translation

"Tudo fica melodia"1 - as palavras do astrólogo, proferidas quando aparecem as imagens de Páris e Helena e do templo grego, evocados por Fausto na segunda parte da tragédia, esssas palavras poderiam referir-se à totalidade dessa obra de Goethe. De fato, a melodia que acompanha a "encenação" do rapto de Helena diante o público da corte imperial no $1^{\circ}$ ato é uma cena de metateatro e a música mágica que emana das proporções do templo e dos passos de Páris irradia como artifício de todos os versos do Fausto.

O próprio Goethe - e muitos críticos - observaram que a obra, sobretudo a segunda parte, tem semelhança à ópera por sua multiplicidade rítmica e a musicalidade dos versos. Em analogia à ópera pode-se pensar até que o verso madrigalesco corresponde ao recitativo, onde a melodia se adequa mais à cadência da linguagem falada, enquanto que os trechos em outros metros correspondem às árias, cavatinas, strette, aos duetos, coros etc, constituindo uma imensa riqueza e diversidade rítmica e melódica. Isso não quer dizer que os diversos metros não serviriam a outras funções, tais

1 "So wie sie wandeln, machen sie Musik./Aus luft'gen Tönen quillt ein Weißnichtwie,/Indem sie ziehn, wird alles Melodie." Na tradução de Jenny Klabin Segall: "Ouve-se a soar música, sons de orquestra./Num não-se-como o aéreo som se amplia / Vai fluindo, e tudo fica melodia." (Goethe 2007, 254 s., v. 6.444-6.446) 
como a expressão de estados emocionais, a caraterização de personagens, tipos sociais ou épocas históricas.

Isto já foi observado por muitos estudiosos do Fausto que contemplaram a forma métrica como elemento relevante da interpretação da obra. Erich Trunz, por exemplo, comentador da chamada edição de Hamburgo observou que "essa plenitude sonante e variada de formas rítmicas é, para um drama, absolutamente inédita”. (Goethe 1998, S. 493) No sentido de Eibl (343) poderíamos falar de uma "semântica do verso" (Verssemantik), na medida em que o efeito se baseia no fato de autor e público disporem das mesmas referências culturais dos esquemas métricos. Até certo ponto, talvez, seria lícito pensar em efeitos universais, como sugere Wolfgang Kayser (100-120); ele acreditava que certos ritmos evocam certas emoções, além dos limites de uma cultura específica.

Portanto, uma tradução em prosa só seria capaz de transmitir o básico, a trama e as falas das personagens, sem considerar os fenômenos mais sutis da poesia. O próprio Goethe, nas notas sobre o West-östlicher Divan, legitimou três tipos de tradução que ele concebia como sequência histórica evolutiva. Para uma primeira aproximação a uma obra em língua estrangeira recomendou a "tradução singela em prosa" porque ela "nos apresenta o estrangeiro à nossa maneira" (Goethe 2010, 31) Num segundo grau, o estrangeiro seria adaptado ao conhecido próprio, da maneira das belles infidèles da tradição francesa. Seria somente no terceiro e último grau da tradução, "que é o mais elevado e último, onde se procura tornar a tradução idêntica ao original, não de modo que um deva vigorar ao invés do outro, mas no lugar do outro." (Goethe 2010, 33) O exemplo que Goethe apresenta é o J. H. Voß que adaptou, nas suas traduções da Ilíada e da Odisseia, o hexámetro grego ao alemão e, por conseguinte, pode-se supor que a adaptação artística, ainda que estranha, do metro original faz parte desse supremo grau da tradução na concepção de Goethe. ${ }^{2}$

${ }^{2}$ A adaptação do hexámetro no alemão foi antecipada por Klopstock na epopeia sobre o Messias; a imitação dos metros gregos é realizada, grosso modo, pela 
Entre as diversas traduções do Fausto para o português brasileiro destaca-se a de Jenny Klabin Segall por sua atenção particular às estruturas métricas. Existe uma meia dúzia ( $c f$. Reichmann) de traduções da tragédia para o português, duas parciais ou completamente em prosa, duas versificadas ainda do século XIX (mas sem maior respeito pela forma do original e sem acesso direto ao original alemão) e uma mais recente para o português europeu feita pelo germanista João Barrento. ${ }^{3} \mathrm{~A}$ obra de Jenny Klabin é a única que considera meticulosamente as estruturas métricas do Fausto e tenta render essas estruturas em versos portugueses. Já na primeira edição de 1943 lemos: "A numeração dos versos desta traducção corresponde à dos versos originaes, e, bem assim, com poucas excepções, o rythmo, a metrificação e a disposição das rimas. - N. da T." (Goethe [1943], 6) Evidentemente, para um texto literário, as equivalências das qualidades estético-poéticas são muito relevantes, mas elas não podem ser tratadas em detrimento dos outros aspectos. A atenção da tradutora se dirige, num primeiro momento, ao significado do texto como um todo e das suas partes, procurando a expressão que represente, na língua e cultura de chegada, aquilo que, de acordo com os leitores comuns e especializados, é o enunciado do original.

A tragédia de Goethe, com seus 12.111 versos, constitui não somente uma das obras mais extensas da literatura europeia (doze vezes o tamanho de Alcestis de Eurípides e três vezes Hamlet). Como já foi observado, ela difere da maioria das peças em língua alemã da época e boa parte da produção do próprio Goethe, por não se apresentar em versos brancos iâmbicos de 5 acentos. Uma versão inicial (chamada "Urfaust" ou Faust, frühe Fassung) ainda mostra amplas passagens em prosa, enquanto que o Faust

substituição de sílabas longas por acentuadas e curtas por não acentuadas, uma vez que a prosódia acentual do alemão não permite basear uma métrica na duração das sílabas, embora Klopstock e Voß tenham feito experimentos nessa direção. $C f$. Burdorf (93 s.), Bunia (96 ss.) e Wagenknecht (2007, 102 ss.).

${ }^{3}$ Essa tradução de João Barrento (Goethe 1999) tem grandes méritos: ela é exata, fluida, clara e, até certo ponto, também se ocupa com a versificação, mas sem considerar a forma métrica tão centralmente como Jenny Klabin.

Cad. Trad., Florianópolis, v. 41, no 3 p. 364-394, set-dez, 2021. 
I é completamente versificado, com exceção de uma única cena curta. As formas usadas por Goethe são as mais diversas. Markus Ciupke (234) registra 37 tipos de versos diferentes, entre os quais alexandrinos, a "Stanzen" (oitavas rimas), versos brancos, trímetros iâmbicos, tetrâmetros trocaicos, terças rimas, versos livres e Knittelverse. O verso mais frequente, no entanto, é o mencionado verso madrigalesco (Madrigalvers) com um número total de 4769 (quase $40 \% ; c f$. Ciupke, 235). Este verso é formado por iambos e pode ter entre 2 e 6 acentos, rimando de forma emparelhada, cruzada ou intercalada. Ele é considerado o verso geral e conversacional do Fausto, usado sobretudo por Mefistófeles. Este personagem se introduz com as palavras "não sei fazer fraseado estético" (v. 275) e sua fala contrasta com os simples e solenes versos iâmbicos de quatro acentos dos hinos cantados pelos anjos no "Prólogo no Céu". Assim, o verso madrigalesco corresponde, dentro da estrutura o drama versificado, à "prosa" da realidade profana e à linguagem pragmático-discursiva. Seu "ritmo maleável e ligeiro [...] sua liberdade métrica, rítmica e rímica" (Mazzari Apud Goethe 2004 , 48) se aproxima da prosa e, de certa forma, este verso "representa" a prosa - um falar neutro - dentro do drama. Transpondo o "princípio ortogonal" da teoria da ficção (Esposito 1998, $278)^{4}$ para a obra versificada, poderíamos dizer: no mundo real existem prosa e poesia, e o mundo ficcional do drama versificado, que representa o mundo, reproduz essa distinção no seu interior. Assim como no interior de um romance existe a distinção entre real e fictício, analogamente à realidade, existe a distinção de prosa e poesia no interior do drama versificado.

Quanto à possibilidade de traduzir aspectos da forma como os metros, existem, no entanto, posições bem céticas como a de Wolfgang Schadewald, que considera:

\footnotetext{
${ }^{4}$ No seu livro sobre a ficcionalidade, Elena Esposito observa que a distinção verdadeiro/falso que se aplica no mundo real, aparece, da mesma forma, dentro das ficções, ou seja, no mundo real, as afirmações do romance são todas "falsas", mas no mundo ficcional do romance se distingue claramente entre aquilo que é verdade neste mundo e aquilo que é ficção ou mentira neste mundo.
} 
Se ele [o tradutor] se decide a favor da palavra e pelo sacrifício da forma externa, esse sacrifício é muito grande, porque toda poesia se realiza na forma sensorial. No entanto, com a forma sensorial, ele sacrifica apenas algo que não é 'traduzível' de nenhuma maneira. [...] A forma sensorial da poesia está indissoluvelmente presa ao som e ao modo da língua de origem. (Schadewaldt: Das Problem des Übersetzens, apud Boetius, 71). ${ }^{5}$

Trata-se, portanto, de um dilema aparentemente insolúvel porque a forma pertence ao mais particular da obra de arte, que na outra língua inevitavelmente deve assumir outra forma individual.

Mas a figura concreta do verso é formada também por padrões estéticos mais abstratos: os metros. Evidentemente a aemulatio dos clássicos produziu durante muito tempo um "tráfico" de formas métricas entre as línguas europeias que estabeleceu uma certa "equivalência" entre certos metros. Assim, o hexâmetro épico grego e romano "gerou" o alexandrino francês, o hendecassílabo italiano, o pentâmetro iâmbico inglês e o decassílabo ${ }^{6}$ português. Essa equivalência "semântica" entre certos metros dentro dos respectivos sistemas literários, no entanto, não significa que as formas sejam, de fato semelhantes. Na realidade, pode-se traduzir palavras e versos, mas não se pode "traduzir" um metro: na tradução de um verso, o tradutor escolhe um metro da poesia da cultura alvo ou cria um metro de acordo com as normas métricas em vigor nessa cultura. Tanto no poema de partida quanto no poema alvo, o metro escolhido serve como grade abstrata e entre essa abstração e a concretude do verso individual se estabece uma tensão. Para Roman Jakobson (1960, 364) esse padrão - que ele chama de "verse design" (figura 1) - não é "um esquema abstrato, teórico", mas um modelo real, subjacente a cada verso concreto - chamado de "verse instance" -, presente tanto na mente do poeta quanto do seu público histórico. Nesse sentido, a

\footnotetext{
5 Todas as traduções são minhas quando não indicado o contrário.

${ }^{6}$ Usamos a terminologia de Castilho: decassílabo é o verso que conta com dez sílabas poéticas até a última tônica.
} 
tradução de textos poéticos deve, em primeiro lugar, refletir sobre o sistema de metros à disposição nas literaturas fonte e alvo.

Figura 1: Esquema de Jakobson / Brogan

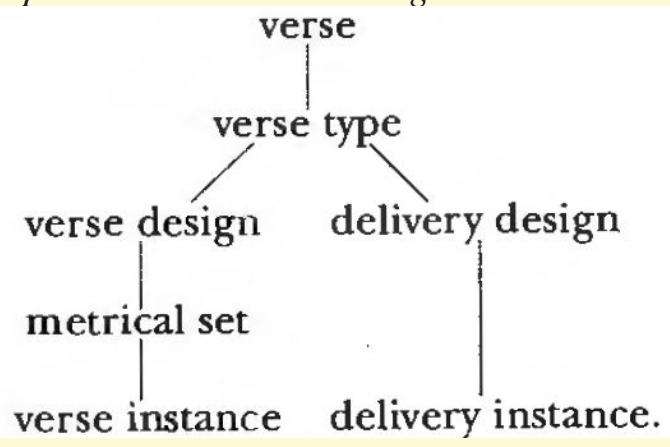

Fonte: (Brogan 1993, 770)

A figura 1 apresenta as distinções do ensaio famoso de Jakobson, publicado em 1960, completado por Terry Brogan. No nível mais alto figura "verse" em distinção à prosa. "Verse type" é definido como tipo de versificação que, geralmente, não é escolhido pelo poeta, mas segue a prosódia ${ }^{7}$ vigente na sua cultura num dado momento: assim os metros dos gregos da fase clássica seguem o tipo quantitativo, as epopeias germânicas da idade média o acentual, as literaturas neolatinas o silábico e as ingleses e alemãs modernas (sobretudo) o silabotônico. ${ }^{8}$ Geralmente se supõe que

\footnotetext{
${ }^{7}$ Quando se fala de "prosódia” deve-se distinguir entre a prosódia como fenômeno da língua e a prosódia literária que constitui uma seleção de elementos da prosódia linguística. Cf. La Driere/Brogan (218), Wagenknecht (17 ss.).

${ }^{8}$ Roman Jakobson $(1960,361)$ reconheceu sistemas silábico, acentuais e quantitativos. Segundo Winslow (872) os sistemas métricos conhecidos se dividem em tipos de acordo com o traço sonoro dominante usado para estabelecer os esquemas métricos: 1) quantidade (duração), 2) acento (volume), 3) sílaba (números), 4) tom (frequência) 5) sintaxe. Autores recentes, com enfoque com as "grandes" literaturas ocidentais, estabelecem tipologias de acordo com a combinação de dois princípios - contagem de sílabas e contagem de ictos (Bunia; Küper) ou, adicionalmente, o terceiro princípio da rima (Wagenknecht). 'Ictus' é considerado uma
} 
essas "escolhas" partem de uma afinidade do tipo de versificação com a prosódia da língua falada que está sujeita à mudança como no caso do alemão na Idade Média. ${ }^{9}$ Até certo ponto, o tipo de versificação também depende de decisões culturais, motivadas por exemplo pelo prestígio de uma certa literatura. ${ }^{10} \mathrm{~A}$ lírica versificada do português do Brasil (PB) segue, como as outras literaturas românicas, o verse type silábico, ou seja, os metros são definidos pelo número de sílabas, com algumas regras adicionais. Nas palavras de Antonio Candido (81): “[...] os tipos possíveis de verso regular nas línguas românicas são classificados não em função dos segmentos, mas em função das sílabas poéticas que contêm.” A poesia alemã desde o renascimento contou com quatro verse types: a) o acentual, b) o silábico, c) o silabotônico e d) uma aproximação ao quantitivo. Enquanto b) e d) permaneceram episódicos, os tipos a) e c) dominaram desde o século XVII e podem ser encontrados no Fausto. Por conseguinte, tanto a análise métrica quanto a tradução da tragédia tornam-se difíceis.

O ramo esquerdo da figura considera os níveis de concretização do verso no poema fixado. O ramo direito se ocupa com a enunciação. Nos dois ramos há o nível do "design": "verse design" é chamado o modelo "abstrato" do verso como por exemplo o hexâmetro grego ou o pentámetro inglês. Os diferentes estilos de recitação como escansão, interpretação sóbria ou enfática etc. Em "instance", Jakobson considera o verso individual na sua concretude sintática e métrica (p. ex. “As armas e os barões assinalados”),

posição forte, indepentemente da qualidade que define a força (duração, volume, frequência).

${ }^{9} \mathrm{Cf}$. Vennemann (Preference laws for syllable structure and the explanation of sound change. With special reference to German, Germanic, Italian, and Latin; "Der Zusammenbruch der Quantität im Spätmittelalter und sein Einfluß auf die Metrik.”), Knapp (2015).

10 "The selection of elements for metrical schematization and of types of schemes is determined in part by the nature of a language, in part by historical accident; one could not have predicted of L[atin] in its pre-classical stage that its classical verse would adopt Gr[eek] schemes." (La Driere/Brogan, 223). Cf. também Bunia sobre "métricas endógenas" e "política cultural" (63 ss.). 
geralmente codificada pela escrita; a performance pessoal e momentânea na oralidade, no entanto, é a "delivery instance". Entre "verse design" e "verse instance" ainda se considera o "metrical set": no caso do hexâmetro uma as múltiplas variantes de substitução de dátilos por espondeus.

Armin Paul Frank (964), estudioso da tradução literária, considera diferentes graus de aproximação da forma métrica do verso alvo à do verso de partida, apresentados aqui no seu Transfer diagram (Figura 2):

Figura 2: Transfer diagram de Armin Paul Frank

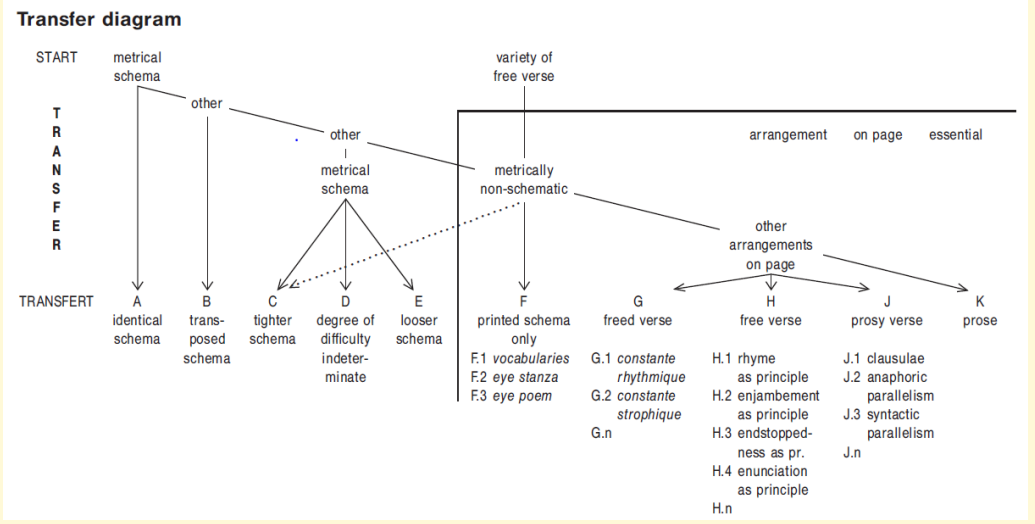

Fonte: (Frank, 965)

A escala abrange desde um transfer "direto" do esquema métrico do texto de partida para o texto alvo até a tradução em prosa. Entre os dois extremos, Armin Paul Frank considera pelo menos oito possibilidades de adaptação: quatro variantes métricas e quatro de verso livre. O que ele chama de "identical schema", na realidade, só é possível, quando muito, se as duas línguas e os tipos de versificação estão tão afins que a estrutura dos versos pode ser considerada "idêntica”. Isso acontece, por exemplo, entre duas prosódias literárias acentuais, o inglês e o alemão: o chamado "blank verse", o verso de Shakespeare e Milton, que foi introduzido na Alemanha na segunda 
metade do século XVIII por Lessing, Wieland e outros. No inglês e no alemão trata-se de versos sem rima que consistem em cinco iambos por vez, ou seja: uma sequência alternante de sílaba átona e tônica. No entanto, quando se trata da adaptação do hexámetro da epopeia grega e latina para a literatura alemã, essa "importação" direta já não é possível, uma vez que a métrica antiga se baseia, em primeiro lugar, na quantidade das sílabas (longa vs. breve) e a métrica do alemão moderno considera o acento (sílaba acentuada $v s$. não acentuada). Os tradutores podem "transpor" o esquema antigo de seis dátilos por verso, substituindo sílabas longas por tônicas e curtas por átonas e isso corresponderia a possibilidade B no esquema de Frank: o transposed schema. O procedimento é facilitado porque, embora as métricas do grego e do alemão se baseiem em prosódias diferentes, os dois sistemas se utilizam de uma distinção binária para constituir o verse design: as sílabas longas/acentuadas podem preencher a posição do downbeat (ictus) do verso e as curtas/não acentuadas preenchem o upbeat (não ictus).

Essa distinção não é a base das prosódias silábicas. ${ }^{11} \mathrm{~A}$ métrica do PB (Português Brasileiro) se serve da contagem de sílabas e, portanto, o arsenal de modelos métricos não se oferece para a transposição dos metros acentuais e silabotônicos do alemão para metros do $\mathrm{PB}$. Isso não quer dizer que a língua portuguesa não conheça acentos e que não haja estruturas rítmicas no interior do decassílabo e os outros metros. No esquema de Jakobson, podemos provavelmente localizar as variantes do decassílabo no nível do metrical set. No sistema grego, como já mencionado anteriormente, a fórmula geral do hexámetro corresponde ao verse design enquanto

${ }^{11}$ A classificação das línguas que parte dos sistemas métricos literários originou um outro debate sobre a classificação da prosódia linguística que perdura até o momento (a palavra chave é a “isocronia”). Há certa evidência que a classificação inteira não tem base fonética em estudos empíricos com medição acústica da fala. Ao mesmo tempo se mantém a distinção entre linguagens acentuais e silábicas sob a perspectiva da percepção por seres humanos. Cf. Auer/Uhmann (1988), Cagliari (2012) e MassiniCagliari (2014). Para a consideração do sistema da versificação brasileira, esse debate não teria consequências imediatas, por isso ela não é considerada neste contexto.

Cad. Trad., Florianópolis, v. 41, no 3 p. 364-394, set-dez, 2021. 
suas variantes com as diversas substituições dos dátilos iniciais por espondeus são considerados diferentes metrical sets desse verso; a Odisseia é escrita inteiramente no hexámetro, mas só poucos versos seguem o metrical set de 5 hexâmetros mais um espondeu. De maneira análoga, os Lusíadas consistem de decassílabos, mas há uma certa variedade entre o "heróico" e o "sáfico"; outra variedade seria o "pentâmetro iâmbico" cuja alternação parece aproximarse aos iambos alemães; voltamos a isso mais adiante. Por enquanto vale constatar que, em nível do tipo de versificação (verse type), a prosódia literária do alemão e do português diferem e, por conseguinte, existe uma grande dificuldade de encontrar metros (verse designs) análogos nas duas línguas. ${ }^{12}$

O Fausto, como já observado, apresenta versos baseados nas prosódias acentual e silabotônica. À primeira pertencem o Knittelvers, um verso arcaico do século XVI com 4 acentos e números irregulares de sílabas não acentuadas, e estrofes dominantemente iâmbicos e trocaicos que retomam a tradição da canção popular. Silabotônica é a maioria dos iambos e troqueus com alternação regular como o madrigalesco; há também sequências datílicas e versos mistos de pés diferentes. Esses são geralmente rimados, mas também ocorrem versos brancos de cinco iambos, de seis iambos (trímetro iâmbico) e de oito troqueus (tetrámetro trocaico). E ainda aparecem "versos livres" avant la lettre, os chamados "freie Rhythmen" que não seguem um metro específico, mas diferem da prosa por seus ritmos enfáticos.

A diferença do tipo prosódico das línguas coloca o tradutor na

\footnotetext{
${ }^{12}$ As variantes dos versos brasileiros muitas vezes são chamadas de variantes rítmicas; o ritmo, porém, pertence aos níveis "verse instance" - a estrutura sintática do verso concreto - e "delivery instance" - a interpretação concreta por um recitador. Ou seja, as variantes 2610 ou 3610 do decassílabo parecem ainda pertencer ao esquema métrico e podem ser preenchidas por palavras que realizam essas posições tônicas com ritmos muito diversos. Candido (67-93) considera o ritmo mais relevante para o efeito estético do verso do que o metro e coincide nisso com teóricos alemães como Wolfgang Kayser (100-120). Chociay (104 s.) distingue 28 variantes "rítmicas" do decassílabo.
} 
situação de optar pela versão E no esquema de Frank (Figura 2): ele pode manter, no verso PB o número determinado de sílabas do verso alemão apresenta, mas não a estrutura métrica do original. Tratando-se de um Knittel ou Volksliedvers nem sequer isso é possível, dado a indeterminação do número de sílabas.

Debruçando-se sobre a tradução de Jenny Klabin, um primeiro exame já comprova sua atenção cuidadosa à diversidade dos esquemas métricos usados por Goethe no Fausto e que ela representa a qualidade polimétrica mediante uma variedade igualmente ampla de metros portugueses. A Tabela 1 pode evidenciar em doze exemplos destacados como ela escolheu para cada tipo de verso alemão um verso diferente em português, de extensão silábica equivalente. Esta tabela, entenda-se, apresenta só uma fração pequena dos versos usados no Fausto I e II (e das suas traduões). Uma análise completa da versificação do Fausto encontra-se nos livros de Ciupke (1994) e de Hartmann (2004).

Tabela 1: Exemplos métricos do Fausto e da sua tradução

\begin{tabular}{|l|l|l|}
\hline Trecho & $\begin{array}{l}\text { verso e/ou estrofe } \\
\text { alemães }\end{array}$ & $\begin{array}{l}\text { verso e/ou estrofe } \\
\text { português }\end{array}$ \\
\hline $\begin{array}{l}\text { Faust I, Zueignung / } \\
\text { Dedicatória } \\
\text { (v. 1-32) }\end{array}$ & $\begin{array}{l}\text { Stanze /oitava rima } \\
\text { ABABABCC } \\
\text { verso iâmbico de cinco } \\
\text { acentos, rimado }\end{array}$ & decassílabo, oitava rima \\
\hline $\begin{array}{l}\text { Faust I, Prolog im } \\
\text { Himmel / Prólogo no céu } \\
\text { (v. 243-270) }\end{array}$ & $\begin{array}{l}\text { Hymnenvers (verso } \\
\text { hínico: verso iâmbico de } \\
\text { quatro acentos, rimado) }\end{array}$ & octossílabo rimado \\
\hline $\begin{array}{l}\text { Faust I, Prolog im } \\
\text { Himmel / Prólogo no céu } \\
\text { (v. 271-365) }\end{array}$ & $\begin{array}{l}\text { Madrigalvers (verso } \\
\text { madrigalesco: } \\
\text { versos iâmbicos com } \\
\text { número variado de } \\
\text { acentos, rimados) }\end{array}$ & $\begin{array}{l}\text { decassílabo e } \\
\text { dodecassílabo rimado }\end{array}$ \\
\hline $\begin{array}{l}\text { Faust I, Nacht / Noite } \\
\text { (v. 354-385) }\end{array}$ & $\begin{array}{l}\text { Knittelvers (versos } \\
\text { rimados de 4 acentos e } \\
\text { livre disposição de sílabas } \\
\text { átonas) }\end{array}$ & $\begin{array}{l}\text { octossílabo e } \\
\text { decassílabo rimado }\end{array}$ \\
\hline
\end{tabular}

Cad. Trad., Florianópolis, v. 41, no 3 p. 364-394, set-dez, 2021. 


\begin{tabular}{|c|c|c|}
\hline $\begin{array}{l}\text { Faust I, Gretchens Stube } \\
\text { / Quarto de Gretchen } \\
\text { (v. 2.759-2.782) }\end{array}$ & $\begin{array}{l}\text { Liedstrophe (estrofe } \\
\text { cancional: verso iâmbico } \\
\text { rimado com } 3 \text { acentos) }\end{array}$ & hexassílabo rimado \\
\hline $\begin{array}{l}\text { Faust I, Wald und Höhle } \\
\text { / Floresta e gruta } \\
\text { (v. 3.217-3.250) }\end{array}$ & $\begin{array}{l}\text { freie Rhythmen (versos } \\
\text { livres brancos: mistura } \\
\text { irregular de pés métricos) }\end{array}$ & $\begin{array}{l}\text { decassílabo e } \\
\text { dodecassílabo, sem } \\
\text { rima }\end{array}$ \\
\hline $\begin{array}{l}\text { Faust I, Walpurgisnacht } \\
\text { / Noite de Valpúrgis (v. } \\
\text { 3.871-3.911) }\end{array}$ & $\begin{array}{l}\text { trochäische Vierheber } \\
\text { (verso trocaico de } 4 \\
\text { acentos) }\end{array}$ & heptassílabo \\
\hline $\begin{array}{l}\text { Faust II, 2. Akt } \\
\text { Fausto II, } 2^{\circ} \text { ato } \\
\text { (v. 8.275-8.284) }\end{array}$ & $\begin{array}{l}\text { daktylische Vierheber } \\
\text { (verso datílico rimado de } \\
4 \text { acentos) }\end{array}$ & $\begin{array}{l}\text { endecassílabo em ritmo } \\
\text { datílico e com rima }\end{array}$ \\
\hline $\begin{array}{l}\text { Faust II, 3. Akt } \\
\text { Fausto II, } 3^{\circ} \text { ato } \\
(\text { v. } 8.488-8.515)\end{array}$ & $\begin{array}{l}\text { reimloser jambischer } \\
\text { Trimeter (trímetro } \\
\text { iâmbico sem rima: } \\
\text { versos iâmbicos de } 6 \\
\text { acentos) }\end{array}$ & dodecassílabo sem rima \\
\hline $\begin{array}{l}\text { Faust II, 3. Akt } \\
\text { Fausto II, 3o ato } \\
\text { (v. 8.909-8.929) }\end{array}$ & $\begin{array}{l}\text { reimloser trochäischer } \\
\text { Tetrameter (tetrâmetro } \\
\text { trocaico sem rima: } \\
\text { versos trocaicos de } 8 \\
\text { acentos) }\end{array}$ & $\begin{array}{l}\text { versos de } 15 \text { sílabas } \\
\text { sem rima }\end{array}$ \\
\hline $\begin{array}{l}\text { Faust II, 4. Akt } \\
\text { Fausto II, } 4^{\circ} \text { ato } \\
\text { (v. 10.849-11.042) }\end{array}$ & $\begin{array}{l}\text { Alexandriner } \\
\text { (Alexandrino: verso } \\
\text { iâmbico rimado de } 6 \\
\text { acentos, cesura e rima) }\end{array}$ & $\begin{array}{l}\text { dodecassílabo rimado, } \\
\text { alexandrino }\end{array}$ \\
\hline $\begin{array}{l}\text { Faust II, 5. Akt } \\
\text { Fausto II, } 5^{\circ} \mathrm{o} \text { ato } \\
(\mathrm{v} .11 .289-11.303)\end{array}$ & $\begin{array}{l}\text { doppelt amphibrachyscher } \\
\text { Vers (verso de } 2 \\
\text { anfíbracos ou versos } \\
\text { datílico-trocáicos com de } \\
2 \text { acentos) }\end{array}$ & $\begin{array}{l}\text { pentassílabo, } \\
\text { redondilha menor de } \\
\text { anfíbracos }\end{array}$ \\
\hline
\end{tabular}

Fonte: O Autor

Lembro que os objetivos explícitos da tradução de Jenny Klabin são manter 1) a numeração dos versos, 2) o ritmo, 3) a metrificação e 4) a disposição das rimas. Cumprir com a primeira e a terceira tarefa já é difícil, uma vez que uma tradução do alemão para o português sempre tende a ser mais extensa do que o original; é de supor que "metrificação" aqui seja entendida como quantidade 
de sílabas, ou seja, a metrificação brasileira respeita o tamanho dos versos alemães, algo que pode ser verificado na tabela: o verso brasileiro corresponde sistematicamente ao número de sílabas alemãs até a última tônica. $\mathrm{O}$ "ritmo" deve referir-se às formas específicas do verso alemão: os iambos, troqueus e, eventualmente, dátilos outros "pés" ${ }^{13}$ Se isso de fato acontece e como é realizado será mostrado no que segue. As rimas da tradução correspondem em muitos casos a forma do modelo, às vezes uma cadência grave é substituída por uma aguda e vice-versa; às vezes a rima aparelhada é rendida por uma rima cruzada.

O poema inicial, a "Dedicatória", é um caso especial. Goethe tematiza o longo processo criativo, no qual o Fausto surgiu, e a voz do "poeta estilizado" (Schöne, 150) se utiliza de iambos de cinco acentos, organizados em estrofes de 8 versos, rimando no esquema ABABABCC. A estrofe que leva o nome "Stanze" foi adaptada da ottave rime do italiano e introduzida na Alemanha só duas décadas antes de Goethe escrever a dedicatória. ${ }^{14}$ Para Jenny Klabin, a escolha da oitava rima deve ter sido óbvia, uma vez que essa estrofe remete também ao modelo italiano e é uma das mais conhecidas e nobres da literatura portuguesa devido a Os Lusíadas; além disso o decassílabo da oitava rima e o "pentâmetro iâmbico" da Stanze apresentam a mesma extensão. Nesse caso, os dois metros dois gênero poético com suas conotações culturais se correspondem em alto grau. Quanto ao ritmo, pode-se primeiro observar o texto alemão. O esquema métrico (x x x x́ x x́ x x́ x x́ x / x x́ x x́ x x́ x x́ x $\mathrm{x}$ ) é realizado no verse instance da seguinte maneira (os números

${ }^{13}$ Embora a teoria métrica alemã atualmente tenha abandonado o uso sistemático dessa categoria da poesia grega antiga porque o verso alemão não seja dividido em unidades menores ( $c f$. Burdorf, $81 \mathrm{~s}$.), parece pertinente mantê-lo na comparação entre os versos de Goethe e sua tradução para o português, particularmente onde não se trata de um ritmo alternante homogêneo, como no caso dos anfíbracos.

${ }^{14}$ A "Dedicatória” foi escrita em 1796 (Schöne, 149); segundo Burdorf (108), era Wilhelm Heinse que introduziu a "Stanze" em 1774. Wieland se serviu da estrofe para suas narrativas versificadas e mostrou sua flexibilidade.

Cad. Trad., Florianópolis, v. 41, no 3 p. 364-394, set-dez, 2021. 
indicam o grau do acento de 1 a $4 ;^{15}$ as sílabas sublinhadas marcam o íctus do metro): 16

$\begin{array}{lllllllllll}2 & 4 & 2 & 3 & 1 & 3 & 1 & 1 & 1 & 4 & 1\end{array}$

Ihr naht euch wieder, schwankende Gestalten,

$\begin{array}{llllllllll}2 & 4 & 2 & 3 & 2 & 3 & 1 & 3 & 1 & 4\end{array}$

Die früh sich einst dem trüben Blick gezeigt.

$\begin{array}{lllllllllll}1 & 4 & 2 & 3 & 2 & 3 & 2 & 4 & 1 & 2 & 1\end{array}$

Versuch ich wohl, euch diesmal festzuhalten?

$\begin{array}{llllllllll}4 & 3 & 2 & 3 & 2 & 2 & 1 & 3 & 1 & 4\end{array}$

Fühl ich mein Herz noch jenem Wahn geneigt?

$\begin{array}{lllllllllll}2 & 3 & 2 & 4 & 2 & 4 & 2 & 3 & 2 & 4 & 1\end{array}$

Ihr drängt euch zu! nun gut, so mögt ihr walten,

$\begin{array}{llllllllll}2 & 3 & 2 & 4 & 2 & 4 & 1 & 3 & 2 & 3\end{array}$

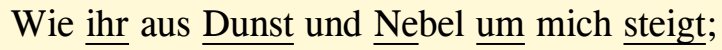

$\begin{array}{lllllllllll}2 & 4 & 1 & 3 & 2 & 3 & 2 & 2 & 1 & 4 & 1\end{array}$

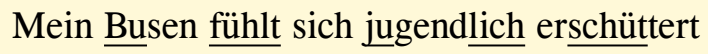

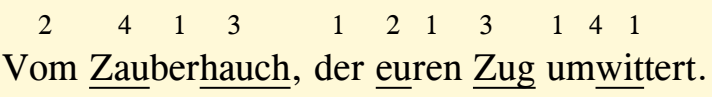

(v. 1-8)

${ }^{15}$ A classificação dos acentos segue Wagenknecht (36 s.).

${ }^{16}$ A determinação do grau segue critérios objetivos como os acentos primários e secundários lexicais, a acentuação de palavras monossilábicas em posição sintáticosemântico destacada; além disso aplica-se a regra geral que dificilmente se encontram, no alemão falado, sequências de dois acentos igualmente fortes (sem pausa) ou de três sílabas completamente átonas; no último caso, a prosódia tende a destacar a sílaba média. Essas regras remetem, por boa parte, a Karl Philipp Moritz, contemporâneo e amigo de Goethe, que publicou seu Versuch einer deutschen Prosodie (1786). Sobre a "alternância dos acentos" em alemão $c f$. Lösener (88 s.) 
Nota-se que todas (quase) as posições do esquema métrico caem em sílabas que levam um acento superior à sílaba imediatamente anterior e posterior. No caso de schwankende no $1^{\circ}$ e o jugendlich no $7^{\circ}$ verso foi aplicada a regra de não haver três sílabas átonas em sequência: instintivamente, a segunda sílaba igualmente átona leva um certo acento leve. $\mathrm{O} 4^{\circ}$ verso apresenta uma licença, uma vez que recitação atenta ao conteúdo colocaria o acento no Fühl em vez do $\underline{i c h} .{ }^{17}$ Trata-se de uma licença muito comum em versos mais extensos como este: a troca do primeiro iambo por um troqueu (a chamada "substituição" $c f$. Bunia, 22). A variante evita a monotonia e leva a atenção particular ao elemento acentuado. Portanto, a distribuição dos acentos prosódicos sobre as posições métricas é regular e equilibrada e, ao mesmo tempo, evita um ritmo "martelado": lido de acordo com o significado das frases, os versos não serão escandidos. Tanto o metro quanto o ritmo da sua realização evocam um ar solene e pensativo e assim apoiam estilo e conteúdo da "Dedicatória" do Fausto.

Na tradução de Jenny Klabin se lê:

Tornais, vós, trêmulas visões, que outrora

Surgiram já à lânguida retina.

Tenta reter-vos minha musa agora?

Inda minha alma a essa ilusão se inclina?

A roda afluis! reinai, então, nesta hora

Em que assomais do fumo e da neblina;

Torna a fremir meu peito com o bafejo

Que vos envolve em mágica o cortejo.

O ritmo interior dos decassílabos pode ser interpretado da seguinte maneira (os números indicam as sílabas tônicas):

${ }_{17}$ No caso, o ich pertence ao rema e o fühl à parte remática da pergunta. $C f$. Schwitalla (57 s.).

Cad. Trad., Florianópolis, v. 41, no 3 p. 364-394, set-dez, 2021. 
Tor|nais, | vós, | trê|mu|las| vi|sões, | que ou|tro|ra 2810

Sur|gi|ram| já| à |lân|gui|da| re|ti|na. $\quad 4610$

Ten|ta $\mid$ re $\mid$ ter $\mid$-vos $|\mathrm{mi}| \mathrm{nha}|\mathrm{mu}|$ sa a $\mid$ go $\mid$ ra? $\quad 4810$

In $\mid$ da $\mid$ mi $\mid$ nha al $\mid$ ma a es $\mid$ sa $\mathrm{i} \mid$ lu| são| se in $\mid$ cli $\mid$ na? 4810

A | ro|da a|fluis!| rei|nai,| en|tão, | nes|ta ho|ra 4610

Em $\mid$ que as $\mid$ so $\mid$ mais $\mid$ do $\mid$ fu $\mid$ mo e $\mid$ da $\mid$ ne $\mid$ bli $\mid$ na; 4610

Tor $\mid$ na a $\mid$ fre $\mid$ mir $\mid$ meu| pei|to| com o| ba|fe|jo 4610

Que| vos| en|vol|ve em| má|gi|ca o| cor|te|jo. $\quad 4610$

A distribuição das tônicas nas sílabas pares notavelmente se aproxima ao esquema do verso iâmbico com os ictos nas posições pares. Uma opção métrica para transpor o verso iâmbico de 5 acentos do alemão para o PB seria o metrical set "pentâmetro iâmbico" do decassílabo com tônica em todas as sílabas pares, exemplificado por Said Ali em versos de Camões e outros (Ali, 89 s.). O mesmo crítico, no entanto, afirma:

O emprego do ritmo uniforme, principalmente sob as formas iâmbica e trocaica, é muito comum na poesia alemã e inglesa, modelando-se por um só tipo de versificação todas ou quase todas as linhas do poema. Nas línguas românicas e, portanto, o português, não falando do verso de doze sílabas, nem dos de onze e dez que dele procederam, as linhas de alternância uniforme entremeiam-se no poema com outras de alternância combinativa. (Ali, 33)

Entre as dez variantes do decassílabo considerados por Said Ali há só três com acentuação exclusiva nas sílabas pares. Os outros colocam acentos nas sílabas 1, 3, 5 ou 7, chegando a um ritmo iâmbico só no final do verso. Essas variantes estabeleceriam necessariamente um ritmo diferente do movimento iâmbico. O fato de Jenny Klabin evitar essas variantes permite deduzir que ela intencionalmente fez duas escolhas. A primeira é a opção pelo decassíla- 
bo com sua tônica obrigatória em sílaba par. A segunda é a seleção de metrical sets que não se afastam do verso alemão.

Essa hipótese é comprovada pelas provas tiradas de outros versos iâmbicos e sua comparação com versos trocaicos de extensão semelhante. No "Prólogo no céu", os arcanjos entoam um hino em versos

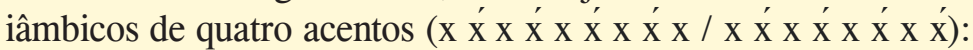

Die Sonne tönt, nach alter Weise,

In Brudersphären Wettgesang,

Und ihre vorgeschriebne Reise

Vollendet sie mit Donnergang.

Ihr Anblick gibt den Engeln Stärke,

Wenn keiner sie ergründen mag;

die unbegreiflich hohen Werke

Sind herrlich wie am ersten Tag.

(v. 243-250)

Nota-se o andamento "grave" e veloz dos versos que imitam os hinos sagrados do culto da igreja católica no início da idade média; Markus Ciupke (35) identifica aqui o esquema de canções sálmicas do barroco.

Jenny Klabin utiliza para o hino em iambos o octossílabo, para Said Ali (77) "pariá das nossas formas poéticas", utilizado por Olavo Bilac na usa "Profissão de fé" em alternação com linhas mais curtas:

O resultado é surpreendente; como no caso do verso par (octossílabo) a última sílaba tônica necesariamente cai numa sílaba par, as tônicas anteriores, com uma certa lógica, ${ }^{18}$ caem também em sílabas pares. No exemplo há só três acentos que escapam desse princípio.

18 Essa lógica se deve ao princípio expresso por Chociay ( 6) que "a Língua Portuguesa apresenta predomínio da alternância binária: as sílabas relevantes se sucedem espaçadas por uma irrelevante, com base na continuidade dos esquemas de alternância $\square \square \square / \quad \square \quad$ ou $\square \quad \square \square /$ [...]”. Cf. também Alvarez, 149-152. 


\begin{tabular}{|c|c|}
\hline Res $\mid$ soa $\mid$ o $\mid$ sol $\mid$ no $\mid$ can $\mid$ to a $\mid$ la $\mid$ do & 48 \\
\hline Dos $\mid$ or $\mid$ bes $\mid$ no in $\mid$ fi| ni| to es $\mid$ pa $\mid$ ço, & 268 \\
\hline $\mathrm{E} \mid$ seu $\mid$ per $\mid$ cur $\mid$ so $\mid$ pré $\mid$-tra $\mid$ ça $\mid$ do & \\
\hline Ven $\mid$ ce $\mid$ com $\mid$ ma $\mid$ jes $\mid$ to $\mid$ so $\mid$ pas $\mid$ so. & \\
\hline $\mathrm{A}|\mathrm{ni}|$ ma os $\mid$ an $\mid$ jos $\mid$ a $\mid$ vi|são & \\
\hline De in|es $\mid$ cru|tá|vel| har|mo|ni|a: & \\
\hline Da o|bra $\mid$ má|xi $\mid$ ma a i $\mid$ men| si $\mid$ dão & \\
\hline Pas $\mid$ ma, $\mid$ qual $\mid$ no $\mid$ pri $\mid$ mei $\mid$ ro $\mid$ di $\mid$ a. & \\
\hline
\end{tabular}

O primeiro verso poderia também ter acentos secundárias nas outras sílabas pares, aproximando-se ao máximo dos iambos bem regulares de Goethe. O quarto, sétimo e oitavo verso, no entanto, apresentam, no seu início, uma inversão do ritmo, com acentos na primeira ou na terceira sílaba. Isso estabelece uma certa variedade, porém, sem invalidar o caráter geral das cadências.

Versos trocaicos encontramos, por exemplo, na "Noite de Valpúrgis", onde Fausto e Mefisto se juntam ao fogo-fátuo numa can-

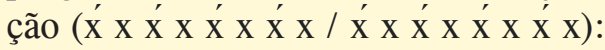

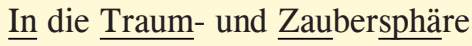

Sind wir, scheint es, eingegangen.

$\underline{\text { Führ }}$ uns gut und mach dir Ehre

$\underline{\mathrm{Da}}$ wir vorwärts bald gelangen

In den weiten, öden Räumen!

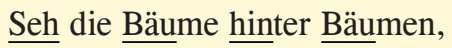

Wie sie schnell vorüberrücken,

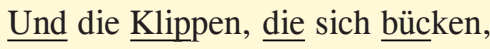

$\underline{\text { Und }}$ die langen Felsennasen,

Wie sie schnarchen, wie sie blasen!

(v. 3.871-3.881)

De acordo com os movimentos confusos do fogo-fátuo e a ascenção escabrosa dos três personagens, o troqueu evoca conotações 
subsidiárias para a dinâmica e para o ambiente meio grotesco da montanha Blocksberg na noite das bruxas. A extensão desses versos é quase idêntica à dos iambos (iambos 8 ou 9 sílabas, troqueus 8 sílabas). Seria possível pensar que, na tradução, aparece somente um tipo de verso, como o octossílabo. Mas isso não acontece. Aqui, Jenny Klabin opta pelo heptassílabo:

\begin{tabular}{|c|c|}
\hline Pe $\mid$ la es $\mid$ fe $\mid$ ra $\mid$ da $\mid$ ma $\mid$ gi $\mid \mathrm{a}$ & 37 \\
\hline $\mathrm{E} \mid$ do $\mid$ so $\mid$ nho, an $\mid$ da $\mid$ mos, $\mid$ ora; & 37 \\
\hline Cum $\mid$ pre o o $\mid$ fí|cio e $\mid$ sê $\mid$ bom $\mid$ gui $\mid a !$ & 37 \\
\hline Por $\mid$ trans $\mid$ por $\mid$ mos $\mid$ sem $\mid$ de $|\mathrm{mo}| \mathrm{ra}$ & 37 \\
\hline As $\mid$ de $\mid$ ser $\mid$ tas, $\mid$ vas $\mid$ tas $\mid$ pla $\mid$ gas. & 37 \\
\hline Vê $\mid$ a $\mid$ des $\mid$ li|zar, | em | va|gas, & 137 \\
\hline Ár|vo|res| en |tre ar|vo|re|dos, & 17 \\
\hline E | ver|gan $\mid$ do $\mid$-se, os $\mid$ ro|che $\mid$ dos; & 37 \\
\hline Co $\mid$ mo e $\mid$ xa $\mid$ lam $\mid$ so $\mid$ pros, $\mid$ ron $\mid$ cos, & 57 \\
\hline Seus $\mid$ na $\mid$ ri $\mid$ zes $\mid$ lon $\mid$ gos, $\mid$ bron $\mid \cos !$ & 57 \\
\hline
\end{tabular}

Bem diferente dos versos do hino, o caráter rítmico que se estabelece aqui se aproxima ao troqueu alemão pelas tônicas nas sílabas ímpares. O elemento mais importante é a escolha do metro: versos pares para iambos, versos ímpares para troqueus. Dessa maneira, a cadência induz um ritmo nas sílabas anteriores que se assemelha ao esquema dos versos alemães sem, de fato, produzir uma alternação monótona na tradução. Pode-se supor que, por exemplo, no verso "Pela esfera da magia", com sílabas tônicas na $3^{\mathrm{a}}$ e $7^{\mathrm{a}}$, o princípio prosódico da alternação entre sílaba tônica e átona ${ }^{19}$ cria um efeito de "acento suspenso" na $1^{\mathrm{a}}$ e na $5^{\mathrm{a}}$ sílaba, ainda que essas não sejam acentuadas na prosa.

Uma amostra aleatória nos demais versos iâmbicos e trocaicos

19 Moraes (181), seguindo Said Ali, considera a alternação binária como caraterística do português do Brasil: In Brazilian Portuguese this secondary stress is governed by a rule of rhythmic alternation of strong $(\mathrm{S})$ and weak $(\mathrm{W})$ syllables, conted from right to left starting from the final tonic." Para Attridge (1196), tratase de um princípio geral da prosódia. 
ensina que o procedimento de Jenny Klabin é sistemático: iambos são rendidos por versos com número de sílabas poéticas par e troqueus com versos como hepta, nona, endecassílabo etc. A escolha do metro par vs. ímpar resulta em que a última sílaba "projeta" o ritmo para o interior do verso, sendo apoiado pela preferência da tradutora por variantes rítmicas alternantes, mas sem alternação rígida como acontece na métrica alemã. $\mathrm{O}$ resultado é que o caráter particular dos dois metros pode ser realizado na tradução brasileira.

Os versos iâmbicos brancos de cinco acentos na cena "Floresta e gruta" são uma variante mais 'nobre' entre os iambos curtos e o madrigalesco. Usados por Goethe na revisão de Ifigênia e sob impressão da Itália clássica, os versos brancos apoiam aqui o ar solene e ênfase da meditação sobre a natureza e o momento existencial: a experiência de amar e ser amado.

Erhabner Geist, du gabst mir, gabst mir alles,

Warum ich bat. Du hast mir nicht umsonst

Dein Angesicht im Feuer zugewendet.

Gabst mir die herrliche Natur zum Königreich, ${ }^{20}$

Kraft, sie zu fühlen, zu genießen. Nicht

Kalt staunenden Besuch erlaubst du nur,

Vergönnest mir, in ihre tiefe Brust

Wie in den Busen eines Freunds zu schauen.

Du führst die Reihe der Lebendigen

Vor mir vorbei und lehrst mich meine Brüder

Im stillen Busch, in Luft und Wasser kennen.

V. 3.217- $\underline{3.227}$

$\mathrm{Na}$ tradução alternam o decassílabo e o dodecassílabo, sem rima como no original; o andamento de tônicas e átonas, com excepção do segundo verso, apoia bem o ritmo iâmbico e a "elevação ao sublime gênio" (Petsch, apud Ciupke, 73):

${ }^{20}$ Este é o único verso com seis em vez de cinco iambos, sem que a bibliografia crítica tenha chegado a um consenso sobre motivo; $c f$. Ciupke (73 s.).

Cad. Trad., Florianópolis, v. 41, no 3 p. 364-394, set-dez, 2021. 
Sub $\mid$ li $\mid$ me $\mid$ Gê $\mid$ nio, | tens $\mid$-me $\mid$ da $\mid$ do $\mid$ tu $\mid$ do, 24810 Tu|do o| que $\mid$ eu| te $\mid$ pe $\mid$ di. $\mid$ Não $\mid$ me $\mid$ mos $\mid$ tras $\mid$ te

Em| vão,| den|tro| do| fo|go, o| teu $\mid$ sem|blan|te.

Por $\mid$ rei|no| des $\mid$ te $\mid-m e$ a in $\mid$ fi|ni|ta $\mid$ na $\mid$ tu $\mid$ re $\mid z a$,

24812

E $\mid$ for $\mid$ ças $\mid$ por $\mid$ senti|-la,| pe|ne|trá|-la.

2610

Não| me ou|tor|gas|te| só| con|ta|to es|tra| nho e| fri|o, 481012

Dei $\mid$ xas $\mid$ te $\mid$-me $\mid$ son $\mid$ dar $\mid$-lhe o| fun|do| sei $\mid$,

26810

Co|mo| se $\mid$ fos $\mid$ se o $\mid$ pei|to $\mid$ de um $\mid$ a $\mid$ mi $\mid$ go.

46810

Ex|pões $\mid$-me a $\mid$ mul|ti|dão| dos $\mid$ se $\mid$ res $\mid$ vi|vos,

26810

E a co|nhe $\mid$ cer, | na| plá|ci|da| sil|vei|ra,

4610

Nos $\mid$ a $\mid$ res, $\mid$ na á|gua, os $\mid$ meus $\mid$ ir $\mid$ mãos, | me en|si|nas. 24810

A estratégia de escolher versos pares para iambos $v s$. ímpares para troqueus pode ser observada até nos metros do $3^{\circ}$ ato do Fausto II onde Goethe adapta o trímetro iâmbico e o tetrámetro trocaico da tragédia grega para "materializar", na linguagem, a figura mítica da Helena e seu coro de moças troianas. De acordo com o caráter desses versos, Jenny Klabin usa o decassílabo e um verso de quinze sílabas, ambos sem rima. Para Albrecht Schöne (580), "o $3^{\circ}$ ato é uma obra de arte métrica de nível supremo." O encontro entre o mundo clássico, representado por Helena de Tróia, e o mundo romântico-moderno, personificado pelo próprio Fausto, acontece, sobretudo, na versificação. O amor incipiente entre os dois personagens se realiza quando Helena deixa de falar no metro clássico e se adapta, no diálogo amoroso com Fausto, aos versos rimados do ocidente cristão. Essa transição se torna esteticamente perceptível na tradução de Jenny Klabin.

O verso madrigalesco, o metro iâmbico de extensão livre mais maleável e dominante nas interações dramáticas da tragédia, é rendido por diversos "versos pares", sem manter-se rigidamente ao número de sílabas do original. Os alexandrinos alemães da cena de entrega dos feudos no $4^{\circ}$ ato, verso ceremonioso e grave do barroco, correspondem aos alexandrinos portugueses de maneira semelhante ao caso da oitava rima e a Stanze, evocando similares conotações histórico culturais, além de apresentar estruturas apro- 
ximadas: 12 sílabas, cesura após a $6^{\mathrm{a}}$ tônica e, no PB, tendência ao ritmo iâmbico.

Um exemplo para versos mais complexos encontra-se no canto de Linceu, do $5^{\circ}$ ato, um trecho extraordinariamente lírico e aperfeiçoado. Goethe combina aqui dois iambos com um anapesto no meio ( $\mathrm{x} \mathbf{x}^{\prime} \mid \mathrm{x}$ x x́ $\left|\mathrm{x} / \mathrm{x} \dot{x}^{\prime}\right| \mathrm{x}$ x x́) cada vez com cadência grave e aguda. Ou, descrito de outra forma, uma combinação de dois anfí-

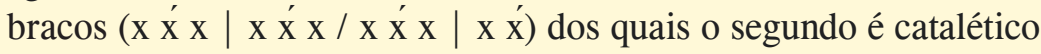
(sem átona final):

Ihr glücklichen Augen,

Was je ihr gesehn,

Es sei wie es wolle,

Es war doch so schön.

(v. 11.300-11.303)

Jenny Klabin escolha novamente um metro que corresponde exatamente ao número de sílabas do verso alemão até a última tônica: a redondilha menor. Mas, neste caso, ela não opta pelas variantes rítmicas a) 3 - 5 ou b) 1 - 3 - 5 de Said Ali (59), ela segue o ritmo "iâmbico-anapéstico" (Chociay, 85), a variante c) 2 - 5, descrito por Ali com as palavras: "Esta última dá mais prazer ao ouvido, já pelo movimento acentuadamente ondulatório, já pela separação mais espaçada dos ictos. Isso explica o vermos muitos poemas compostos unicamente com este ritmo anfibráquico.” (59)

$\begin{array}{ll}\text { Fe } \mid \text { li } \mid \text { zes } \mid \text { meus } \mid \text { o } \mid \text { lhos, } & 25 \\ \text { O } \mid \text { que heis } \mid \text { per } \mid \text { ce } \mid \text { bi } \mid \text { do, } & 25 \\ \text { Lá| se } \mid \text { ja o } \mid \text { que } \mid \text { for, } & 25 \\ \text { Tão } \mid \text { be } \mid \text { lo } \mid \text { tem } \mid \text { sido! } & 25\end{array}$

Um maior problema do que versos com estruturas mais regulares apresenta o Knitttelvers, modelado a partir da prosódia pré-mo- 
derna. Já para o ouvido dos alemães contemporâneos, o esquema de 4 acentos sem qualquer regra para o preenchimento por sílabas átonas soa arcaico e tenso, o que espelha, no famoso monólogo inicial do protagonista, tanto sua posição entre Idade Média e Renascimento quanto seu agitado estado de ânimo. O número de sílabas pode variar de 8 a 11 sílabas e a posição das tônicas não obedece a uma alternação consequentemente iâmbica ou trocaica: ${ }^{21}$

Habe nun, ach! Philosophie,

Juristerei und Medizin,

Und leider auch Theologie

Durchaus studiert, mit heißem Bemühn.

Da steh ich nun, ich armer Tor!

Und bin so klug als wie zuvor;

Heiße Magister, heiße Doktor gar

Und ziehe schon an die zehen Jahr

Herauf, herab und quer und krumm

Meine Schüler an der Nase herum -

Und sehe, daß wir nichts wissen können!

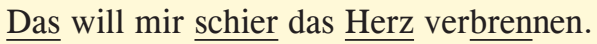
(v. 354-365)

$\dot{\mathrm{x}} \mathrm{x}$ x $\dot{\mathrm{x}}^{\prime} \dot{\mathrm{x}} \mathrm{x} \mathrm{x} \dot{\mathrm{x}}$

$\mathrm{x} \dot{\mathrm{x}} \mathrm{x} \times \mathrm{x}^{\prime} \mathrm{x} \dot{\mathrm{x}} \mathrm{x} \dot{\mathrm{x}}$

$\mathrm{x} \dot{\mathrm{x}} \mathrm{x} \dot{\mathrm{x}} \dot{\mathrm{x}} \mathrm{x} \mathrm{x} \dot{\mathrm{x}}$

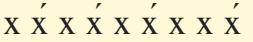

$\mathrm{x} \dot{\mathrm{x}} \mathrm{x} \quad \dot{\mathrm{x}} \mathrm{x} \dot{\mathrm{x}} \mathrm{x}$ x

$\mathrm{x} \dot{\mathrm{x}} \mathrm{x} \quad \mathrm{x}^{\prime} \mathrm{x} \dot{\mathrm{x}} \mathrm{x} \quad \mathrm{x}^{\prime}$

x $\mathrm{x}$ x $\dot{\mathrm{x}}^{\prime} \mathrm{x} \mathrm{x}_{\mathrm{x}} \mathrm{x} \dot{\mathrm{x}} \mathrm{x}$

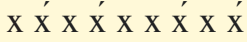

$\mathrm{x} \dot{\mathrm{x}} \mathrm{x} \times \mathrm{x}^{\prime} \mathrm{x} \dot{\mathrm{x}} \mathrm{x} \dot{\mathrm{x}}$

$\mathrm{x}$ x $\dot{\mathrm{x}}^{\prime} \mathrm{x} \dot{\mathrm{x}} \mathrm{x} \dot{\mathrm{x}} \mathrm{x} \mathrm{x} \dot{\mathrm{x}}$

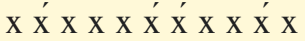

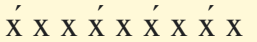

Como se mencionou, não há nenhum verso português que corresponda a essa forma alemã, e a prosódia silábica está mais alheia à prosódia acentual do Knittel do que à prosódia silabotônica dos outros versos. Na tradução de Jenny Klabin notamos que ela usa, de forma flexível, dois versos diferentes, o octossílabo e o decassílabo, sem que sua posição corresponda exatamente à dos versos mais longos do original; mas o efeito de irregularidade e inquietação atribuído ao efeito estético desse monólogo se mantém devido à escolha de algumas variantes rítmicas com sílabas ímpares. Como

${ }^{21}$ Devido à ausência de um esquema métrico que defina as posições dos quatro acentos, existem outras possibilidades de interpretar essas linhas. A versão apresentada corresponde à recitação por Bruno Ganz na gravação da encenação de Peter Stein (Goethe 2007). 
no original, ela faz uso de rimas aparelhadas e cruzadas sem colocá-las exatamente nas mesmas posições.

\begin{tabular}{|c|c|}
\hline $\mathrm{Ai} \mid$ de $|\operatorname{mim} !|$ da $\mid$ fi $\mid$ lo $\mid$ so $\mid$ fia, & 138 \\
\hline Me $\mid$ di $\mid$ ci $\mid$ na, $\mid$ ju $\mid$ ris $\mid$ pru $\mid$ dên $\mid$ cia, & 38 \\
\hline E,| mí|se |ro eu!| da| teo|lo|gia, & 268 \\
\hline $\mathrm{O}$ es $\mid$ tu $\mid$ do $\mid$ fiz, $\mid$ com $\mid$ má $\mid$ xi $\mid$ ma in $\mid$ sis $\mid$ tên $\mid$ cia. & 4610 \\
\hline Po $\mid$ bre $\mid$ sim $\mid$ pló| rio, a $\mid$ qui $\mid$ es $\mid$ tou & 468 \\
\hline E | sá|bio | co|mo| dan|tes| sou! & 68 \\
\hline De $\mid$ dou $\mid$ tor $\mid$ te $\mid$ nho o $\mid$ no $\mid$ me e $\mid$ mes $\mid$ tre em $\mid$ ar $\mid$ tes, & 36810 \\
\hline E |le $\mid$ vo $\mid$ dez $\mid$ a $\mid$ nos $\mid$ por $\mid$ es $\mid$ tas $\mid$ par $\mid$ tes, & 2810 \\
\hline Pra | cá $\mid$ e $\mid$ lá, | a $\mid$ qui ou a $\mid$ co|lá & 248 \\
\hline Os $\mid$ meus $\mid$ dis $\mid$ cí $\mid$ pu $\mid$ los $\mid$ pe $\mid$ lo $\mid$ na $\mid$ riz. & 410 \\
\hline E |ve|jo-o,| não $\mid$ sa $\mid$ be $\mid$ mos $\mid$ na $\mid$ da! & \\
\hline Dei $\mid$ xa $\mid$-me a $\mid$ men $\mid$ te a $\mid$ mar $\mid$ gu $\mid$ ra $\mid$ da. & 148 \\
\hline
\end{tabular}

Pode-se constatar que o efeito estético se aproxima ao dos versos alemães sem romper as regras da versificação portuguesa. ${ }^{22} \mathrm{~A}$ mesma estratégia encontra-se nos versos livres da cena "Jardim de Marta". Os chamados "freie Rhythmen" constituíram uma conquista mais avançada de Klopstock, em consequência dos seus experimentos com a adaptação dos metros da ode grega. Em analogia à ode de Píndaro e aos salmos bíblicos, essa forma de verso livre mas ritmizado foi usado em contextos do hino da divindade para expressar a elevação mais sublime do ânimo em êxtase. Na fase de "Tempestade e ímpeto", Goethe se serviu desse gênero em poemas como "Prometheus, Ganymed e Wanderers Sturmlied" (Canção do caminhante). À mesma época, escreveu a maior parte da tragédia de Margarida incluindo essa cena. Em resposta à famosa pergunta de Gretchen ("Dize-me, pois, como é com a religião?”, v. 3415), Fausto responde com um discurso enfático sobre sua fé panteísta

22 Parece que no chamado "Passeio de Páscoa" da cena "Diante das portas da cidade" (v. 903-940), a tradutora até inseriu alguns versos ímpares entre os octo e decassílabos para representar a irregularidade do metro. 
(cf. Schöne, 324). Os versos compreendem geralmente um sintagma inteiro; o número de acentos abrange de um até quatro e não há nenhuma regularidade na alternação com sílabas não acentuadas. Podem ocorrer até três sílabas tônicas em seguida ("Glück! Herz! Liebe!"). No início ainda há rimas que se perdem após o sexto verso. De forma geral, os freie Rhythmen seguem a prosódia da língua falada, mas alguns recursos (cesura no final do verso, inversões, paralelismos) constituem uma ritmicidade ausente na prosa.

Wer darf ihn nennen?

Und wer bekennen:

Ich glaub ' ihn.

Wer empfinden,

Und sich unterwinden

$\mathrm{Zu}$ sagen: ich glaub' ihn nicht?

Der Allumfasser,

Der Allerhalter,

Faßt und erhält er nicht

Dich, mich, sich selbst?

Wölbt sich der Himmel nicht dadroben?

Liegt die Erde nicht hierunten fest?

Und steigen freundlich blickend

Ewige Sterne nicht herauf?

Schau' ich nicht Aug' in Auge dir,

Und drängt nicht alles

Nach Haupt und Herzen dir,

Und webt in ewigem Geheimnis

Unsichtbar sichtbar neben dir?

Erfüll davon dein $\underline{\text { Herz }}$, so groß es ist,

Und wenn du ganz in dem Gefühle selig bist,

$\underline{\text { Nenn }}$ es dann, wie du willst,

Nenn's Glück! Herz! Liebe! Gott!

Ich habe keinen Namen

Dafür! Gefühl ist alles;

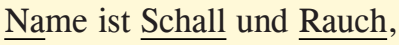

Umnebelnd Himmelsglut.

(v. $\overline{3.432-3 . \overline{458})}$ 


\begin{tabular}{|c|c|}
\hline Quem $\mid$ o $\mid$ po $\mid$ de $\mid$ no $\mid$ mear? & 136 \\
\hline Quem| pro|fes | sar: & 24 \\
\hline $\mathrm{Eu} \mid$ cre $\mid$ io| ne $\mid$ le? & 24 \\
\hline Quem $\mid$ con $\mid$ ce $\mid$ ber & 14 \\
\hline E ou|sar| di|zer: & 24 \\
\hline Não| cre $\mid$ io $\mid$ ne $\mid$ le? & 14 \\
\hline $\mathrm{E}|\mathrm{le}$,$| do \mid$ to $\mid$ do o a $\mid$ bran $\mid$ ge $\mid$ dor, & 148 \\
\hline $\mathrm{O}$ u|ni|ver|sal| sus|ten|ta|dor, & 48 \\
\hline Não $\mid$ a $\mid$ bran $\mid$ ge e $\mid$ não $\mid$ sus $\mid$ tém $\mid$ e $\mid$ le & 38 \\
\hline $\mathrm{A} \mid$ ti, $\mid$ a $\mid$ mim, $\mid$ co $\mid$ mo a $\mid$ si $\mid$ pró $\mid$ prio? & 248 \\
\hline Lá| no al $\mid$ to $\mid$ não $\mid$ se ar $\mid$ que $\mid$ ia o $\mid$ céu? & 268 \\
\hline Não jaz $\mid$ a $\mid$ te $\mid$ rra a $\mid$ qui| em|bai|xo, | fir|me? & 246810 \\
\hline E em $\mid$ bri $\mid$ lho $\mid$ sua $\mid$ ve $\mid$ não $\mid$ se e $\mid$ le |vam & 2468 \\
\hline $\mathrm{Pe}|\mathrm{re}|$ nes $\mid$ as $\mid$ tros $|\mathrm{pa}| \mathrm{ra}$ o $\mid$ al $\mid$ to? & 48 \\
\hline Não $\mid$ fi $\mid$ ta o $\mid$ meu $\mid$ o $\mid$ lhar $\mid$ o $\mid$ teu, & 268 \\
\hline $\mathrm{E} \mid$ não $\mid$ pe $\mid$ ne $\mid$ tra $\mid$ tu $\mid$ do & 26 \\
\hline Ao $\mid$ co|ra|ção| e ao juí|zo| teu, & 468 \\
\hline E o|bra in $\mid$ vi| sí|vel, | em $\mid$ mis|té| rio e $\mid$ ter $\mid$ no, & 4810 \\
\hline Vi| si|vel $\mid$ men $\mid$ te ao $\mid$ la $\mid$ do $\mid$ teu? & 468 \\
\hline Dis $\mid$ so en $\mid$ che o $\mid$ co $\mid$ ra $\mid$ ção, $\mid$ a $\mid$ té ao $\mid$ ex $\mid$ tre $\mid$ mo. & 2610 \\
\hline E $\mid$ quan $\mid$ do $\mid$ trans $\mid$ bor $\mid$ dar $\mid$ de um| êx $\mid$ ta $\mid$ se $\mid$ su $\mid$ pre $\mid$ mo, & 6812 \\
\hline En|tão $\mid$ no $\mid$ me $\mid$ ia-o $\mid$ co $\mid$ mo $\mid$ quei $\mid$ ras, & 48 \\
\hline Ven|tu|ra! a|mor!| co|ra|ção!| Deus! & 2478 \\
\hline Não $\mid$ te $\mid$ nho $\mid$ no $\mid$ me $\mid$ pa|ra $\mid$ tal! & 248 \\
\hline $\mathrm{O} \mid$ sen $\mid$ ti $\mid$ men $\mid$ to é $\mid$ tu $\mid$ do; & 46 \\
\hline No $\mid$ me é| va|por $\mid$ e $\mid$ som, & 46 \\
\hline $\mathrm{Nu}$ blan $\mid$ do ar $\mid$ dor $\mid$ ce les $\mid$ te. & 46 \\
\hline
\end{tabular}

Os metros da tradução oscilam entre 4 e 12 sílabas, sempre versos pares, e com grande variação de modelos rítmicos. A homogeneidade do ritmo nos versos iniciais e finais reforça a estrutura retórica. A sequênia 2478 (Ventura! amor! coração! Deus!) deve ser tão incomum e tão expressiva no contexto da poesia brasileira como verso correspondente do original na literatura alemã.

Evidentemente, não é viável, nesse artigo, apresentar toda a riqueza métrica do Fausto e da sua tradução. Os exemplos aqui tratados, porém, deviam dar uma ideia da grande maleabilidade 
da tradutora. Espera-se que as análises possam convencer aqueles que consideram questões métricas negligenciáveis para a tradução. Pelo menos confirmaram que o propósito da primeira edição de 1943 foi cumprido magistralmente por Jenny Klabin Segall que, na minha opinião, merece mais atenção pelos estudos da tradução.

\section{Agradecimento:}

Este trabalho foi realizado com apoio do Conselho Nacional de Desenvolvimento Científico e Tecnológico (CNPq).

\section{Referências}

Ali, Manuel Said. Versificação portuguesa. São Paulo: Edusp, 1999.

Alvarez, Beethoven. "A teoria do metro de Fabb \& Halle e o decassílabo português”. Cadernos de Estudos Linguísticos, vol.56, 1, (2014). 141-180.

Attridge, D[erek]. "Rhythm". The Princeton encyclopedia of poetry and poetics, Greene, Roland, et al. (orgs.). [Princeton]: Princeton University Press 2012. pp. 1195-1198.

Auer, Peter; Susanne Uhmann. "Silben- und akzentzählende Sprachen. Literaturüberblick und Diskussion." Zeitschrift für Sprachwissenschaft, vol. 7, $\mathrm{n}^{0} .2$, (1988): 214-59.

Boetius, Susanne. Die Wiedergeburt der griechischen Tragödie auf der Bühne des 19. Jahrhunderts. Berlin: de Gruyter, 2005.

Brogan, T. V. F. "Meter." The New Princeton encyclopedia of poetry and poetics, edited by Alex Preminger and T. V. F. Brogan, Princeton University Press, 1993, pp. 768-83. 
Bunia, Remigius. Metrik und Kulturpolitik. Verstheorie bei Opitz, Klopstock und Bürger in der europäischen Tradition. Berlin: Ripperger \& Kremers, 2014.

Burdorf, Dieter. Einführung in die Gedichtanalyse. 3., aktualisierte und erweiterte Auflage, Verlag J.B. Metzler, 2015.

Cagliari, Luiz Carlos. "Línguas de ritmo silábico." Revista de Estudos Linguísticos, vol. 20, $\mathrm{n}^{\mathrm{o}}$. 2, (2012): 23-58.

Candido, Antonio. O estudo analítico do poema. São Paulo: Humanitas, 2006.

Chociay, Rogério. Teoria do verso, McGraw-Hill, 1974.

Ciupke, Markus. "Des Geklimpers vielverworrner Töne Rausch”. Die metrische Gestaltung in Goethes Faust. Göttingen Wallstein, 1994.

Eibl, Karl. Das monumentale Ich - Wege zu Goethes Faust. Frankfurt a.M.: Insel, 2000 .

Esposito, Elena. Fiktion und Virtualität. Medien, Computer, Realität. Krämer, Sybille (org.). Frankfurt a.M.: Suhrkamp, 1998, pp. 269-296.

Frank, Armin Paul. "Versification and stanza formation: Towards a transfer approach." Übersetzung - Translation - Traduction: 1. Teilband, Harald Kittel et al. (Ed.). Berlin: de Gruyter, 2004, pp. 963-980.

Goethe, Johann Wolfgang. Fausto. Uma tragedia. Primeira parte. Tradução de Jenny Klabin-Segall. São Paulo: Companhia Editora Nacional, s.a. [1943].

Goethe, Johann Wolfgang. Faust. Erich Trunz (Ed.). Hamburger Ausgabe in 14 Bänden, vol. 3, Dramen I). dtv, 1998.

Goethe, Johann Wolfgang. Fausto, Tradução de João Barrento. Lisboa: Relógio D’Água, 1999.

Goethe, Johann Wolfgang. Fausto. Uma tragédia. Primeira parte. Ed. bilíngue de Marcus Mazzari; tradução de Jenny Klabin-Segall. São Paulo: editora 34, 2004. 
Goethe, Johann Wolfgang. Faust. Inszenierung von Peter Stein. (2000) 4 DVDs. Arles: Harmonia Mundi / Theater Edition, 2007.

Goethe, Johann Wolfgang. Fausto. Uma tragédia. Segunda parte. Ed. bilíngue de Marcus Mazzari; tradução de Jenny Klabin-Segall. São Paulo: Editora 34, 2007.

Goethe, Johann Wolfgang. "Drei Stücke vom Übersetzen - Três trechos da tradução." Tradução de Roswitha Friesen Blume. Clássicos da teoria da tradução. Antologia Bilíngue: Volume 1. Alemão-Português, $2^{\mathrm{a}}$ edição, revisada e ampliada. Werner Heidermann (Ed.). Florianópolis: Universidade Federal de Santa Catarina, 2010, 28-35.

Hartmann, Tina. Goethes Musiktheater. Singspiele, Opern, Festspiele, „Faust«. Berlin: de Gruyter, 2004.

Jakobson, Roman. "Linguistics and Poetics." Sebeok, Thomas A. (org.) Style in Language. New York, London: Massachussetts Institute of Technology 1960: pp. 350-377; 435-449.

Kayser, Wolfgang. Kleine deutsche Versschule. Bern, München: Francke, 1986.

Küper, Christoph. Sprache und Metrum. Semiotik und Linguistik des Verses. Tübingen: Max Niemeyer, 2017.

Knapp, Fritz Peter. "Alle 600 Jahre kam der deutsche Geist sozusagen wieder dran”. Beiträge zur Geschichte der deutschen Sprache und Literatur, vol.137, 4, (2015): 599-622.

La D[riere[, J[ames] C[raig], and T. V. F. B[rogan]. "Prosody." The Princeton Handbook of Poetic Terms, edited by Alex Preminger et al., Princeton University Press, 1986, pp. 218-23.

Lösener, Hans. Der Rhythmus in der Rede. Linguistische und literaturwissenschaftiche Aspekte des Sprachrhythmus, Niemeyer, 1999.

Massini-Cagliari, Gladis. "Três momentos da história da acentuação portuguesa." Web-Revista Sociodialeto, vol. 4, no. 12, (2014): 555-74.

Moraes, João. "Intonation in Brazilian Portuguese”. Intonation Systems. A Survey of Twenty Languages. Hirst, Daniel; Di Cristo, Albert (orgs.). Cambridge: Cambridge University Press 1998. pp. 179-194. 
Moritz, Karl Philipp. Versuch einer deutschen Prosodie, Berlin: Arnold Wever, 1786. http://db.saur.de/DLO/saveUrl.jsf?type $=$ fullcitation\&documentId = BDL0 2121_0001\&volumeId=BDL02121_0001\&user = fuberlin.

Reichmann, Tinka. "Frases célebres do Fausto: um desafio para a tradução." Pandaemonium Germanicum. nº. 12, (2008): 191-209.

Schöne, Albrecht. Faust. Kommentarband. (Frankfurter Ausgabe, vol, I,7/ 2). Frankfurt a. M.: Deutscher Klassiker Verlag, 1994.

Schwitalla, Johannes. Gesprochenes Deutsch. Eine Einführung. 4., neu bearb. und erw. Aufl., Schmidt, 2012.

Trunz, Erich. "Kommentar". Erich Trunz (Ed.) Faust. Goethes Werke (Hamburger Ausgabe in 14 Bänden, vol. 3, Dramen I). München: dtv, 1998.

Vennemann, Theo. Preference laws for syllable structure and the explanation of sound change. With special reference to German, Germanic, Italian, and Latin. Berlin, New York: Mouton de Gruyter, 1988.

Vennemann, Theo. "Der Zusammenbruch der Quantität im Spätmittelalter und sein Einfluß auf die Metrik." Amsterdamer Beiträge zur Älteren Germanistik, vol. 42, (1995): 185-223.

Wagenknecht, Christian. Deutsche Metrik. Eine historische Einführung. 5., erweiterte Auflage. München: Beck, 2017.

Winslow, R. "Meter." The Princeton encyclopedia of poetry and poetics, edited by Roland Greene et al., 4 ed. Princeton: Princeton University Press, 2012, pp. 872-876.

Recebido em: $11 / 04 / 2021$

Aceito em: 28/07/2021

Publicado em setembro de 2021

Helmut Paul Erich Galle. E-mail: helmut_galle@hotmail.com. ORCID: https:// orcid.org/0000-0001-8563-6080. 